\title{
Dosimetric application of green luminescence in irradiated TLD-500 detectors
}

\author{
A.S. Vokhmintsev*, I.A. Weinstein, V.S. Kortov \\ Ural Federal University, Mira 19, 620002 Yekaterinburg, Russian Federation
}

\section{H I G H L I G H T S}

- 3D plots of TL emission in $\alpha-\mathrm{Al}_{2} \mathrm{O}_{3}$ crystals before and after UV irradiation at $623 \mathrm{~K}$

- First-order kinetic processes prevail during thermoluminescence at the $2.4 \mathrm{eV}$ band.

- Observed dose dependences of the green TL light sum are linear in $10^{-5}-1 \mathrm{~Gy}$ range.

\section{A R T I C L E I N F O}

\section{Article history:}

Received 15 October 2012

Received in revised form

17 January 2013

Accepted 19 January 2013

\section{Keywords:}

Aluminum oxide

First-order kinetic

F2-center

Interstitial aluminum

TL dosimetry

\begin{abstract}
A B S T R A C T
The spectral and kinetic characteristics of thermoluminescence (TL) for anion-defective $\alpha-\mathrm{Al}_{2} \mathrm{O}_{3}$ single crystals in the $4.4-2.2 \mathrm{eV}$ range at $300-600 \mathrm{~K}$ were studied. Three-dimensional (3D) plots of the luminescence under research for a sample before and after UV irradiation at $623 \mathrm{~K}$ for 30 min were analyzed. The increase in the emission response in the 2.4 and $3.7 \mathrm{eV}$ bands for the sample after the photothermal treatment was observed. The dominant contribution of a thermally stimulated process with first-order kinetics in the regularities of the $2.4 \mathrm{eV}$ luminescence was shown. The linearity of the dose dependences for the $2.4 \mathrm{eV}$ TL response in different samples at $10^{-5}-1 \mathrm{~Gy}$ was demonstrated. The advantage of using the green thermoluminescence in the TLD-500 for solid state dosimetry was discussed.
\end{abstract}

(c) 2013 Elsevier Ltd. All rights reserved.

\section{Introduction}

Anion-defective $\alpha-\mathrm{Al}_{2} \mathrm{O}_{3}$ single crystals are widely used in the solid state dosimetry of ionizing radiation as TLD-500 detectors based on the thermoluminescent (TL) technique (Akselrod et al., 1990). The absorbed dose is determined by the TL yield within a wide spectral range (Akselrod et al., 1990; McKeever et al., 1999). As a rule, investigations of the dose dependences of the different TL parameters of $\alpha-\mathrm{Al}_{2} \mathrm{O}_{3}$ crystals, both for fundamental and applied studies, are not focused on selective luminescence bands. Unfortunately, such an analysis does not account for the useful complementary information concerning the luminescence in various spectrum regions. This oversight may lead to false conclusions about the mechanisms and kinetics of the TL processes under study. Measurements of the TL with spectral resolution allow a detailed investigation of the luminescence features and provide necessary data for a deeper understanding of the main mechanisms and regularities of the TL in $\alpha-\mathrm{Al}_{2} \mathrm{O}_{3}$ crystals.

\footnotetext{
* Corresponding author. Tel.: +7 343375 9374; fax: +7 3433759373.

E-mail address: a.s.vokhmintsev@ustu.ru (A.S. Vokhmintsev).
}

It is known that the spectral response of the TLD-500 consists of several components. The luminescence spectra have the emission bands of oxygen vacancies with two or one captured electrons, viz., $3.0 \mathrm{eV}$ (F-centers) and $3.8 \mathrm{eV}\left(\mathrm{F}^{+}\right.$-centers), respectively, as well as the bands of $\mathrm{Cr}^{3+}$ impurity defects $(1.8 \mathrm{eV})$, among others (Evans et al., 1994; Kotomin and Popov, 1998). The F-centers are the main contributors to the overall TLD-500 luminescence signal, from which the absorbed dose is estimated. At the same time, a number of papers report a weaker luminescence in the $2.4 \mathrm{eV}$ band, which is attributed to defects in the anion sublattice ( $F_{2}$-centers) (Evans et al., 1994; Kotomin and Popov, 1998; Pelenyov et al., 2001; Tale et al., 1996) or to interstitial aluminum atoms $\left(\mathrm{Al}_{\mathrm{i}}^{+}-\right.$centers) (Evans and Stapelbroek, 1980; McKeever et al., 1999; Springis and Valbis, 1984; Vokhmintsev, 2009). Different luminescence mechanisms were suggested for the green spectral region. For example, Evans and Stapelbroek (1980), concluded that interstitial aluminum was responsible for the reabsorption of the $3.8 \mathrm{eV}$ emission and further bleaching in the $2.4 \mathrm{eV}$ band. A radiationless transfer of energy from $\mathrm{F}$ - to $\mathrm{Al}_{\mathrm{i}}^{+}$-centers as the main excitation channel was discussed by Arutyunyan et al. (1995). However, in our opinion, the role of the $2.4 \mathrm{eV}$ luminescence in the TL response of irradiated $\alpha$ - 
$\mathrm{Al}_{2} \mathrm{O}_{3}$ crystals has not been sufficiently discussed in the literature. There are no data about the dose and energy responses, the highdose range, the sensitivity, or the effect of fading under different types of irradiation. The above properties of TL detectors must be known for their possible use in solid state dosimetry (Chen and McKeever, 1997).

The aim of the present study was to investigate the TL features of dosimetric $\alpha-\mathrm{Al}_{2} \mathrm{O}_{3}$ (TLD-500) crystals in the $2.4 \mathrm{eV}$ band while varying the $\beta$-radiation dose.

\section{Samples and techniques}

$\alpha-\mathrm{Al}_{2} \mathrm{O}_{3}$ single crystals were grown by Stepanov's method in a strongly reduced atmosphere and had a high oxygen nonstoichiometry. The final samples were discs that were $5 \mathrm{~mm}$ in diameter and $1 \mathrm{~mm}$ in thickness. Four samples were used in the study. The sensitivity of the samples to $\beta$-radiation was evaluated by the TLyield in the $3.0 \mathrm{eV}$ band after irradiation with a test dose of $64 \mathrm{mGy}$. The sensitivity was found to be similar to within $\pm 10 \%$ for all four samples.

The temperature dependences of the spectra were analyzed for sample 1 . The TL was registered within the $280-570 \mathrm{~nm}$ (4.43$2.18 \mathrm{eV}$ ) spectral range with a step of $10 \mathrm{~nm}$ using a MUM grating monochromator and FEU-39A photomultiplier in a counting mode. The TL curves were measured within the 300-600 K range with a constant heating rate of $2 \mathrm{~K} / \mathrm{s}$ for a test dose $D=96 \mathrm{mGy}$. First, the measurements were performed for sample 1 in the initial state. Next, the crystal was subjected to a photothermal treatment with unfiltered UV irradiation from a DRT-230 $\mathrm{Hg}$ lamp for $30 \mathrm{~min}$ at $623 \mathrm{~K}$. It is known that as a result of such an impact, the deep traps are filled due to the active photoconversion of the $\mathrm{F}$ - and $\mathrm{F}^{+}$-centers, and the TL yield of the TLD-500 detectors in different luminescence bands increases (Weinstein et al., 2002; Vokhmintsev, 2009). Then, TL measurements at different emission wavelengths were performed for the UV-irradiated sample 1 . The temperature dependences of the spectra were normalized by the PMT photocathode sensitivity.

The dose dependences of the remaining three samples were studied only for their initial states. To accumulate the required dose within the $D_{1}=10^{-5}-10^{-2}$ Gy and $D_{2}=5 \cdot 10^{-3}-10^{2}$ Gy ranges, the detectors were exposed to $\beta$-radiation from the ${ }^{90} \mathrm{Sr} /{ }^{90} \mathrm{Y}$ sources with a dose rate of $20 \mu \mathrm{Gy} / \mathrm{min}$ or $32 \mathrm{mGy} / \mathrm{min}$, respectively. To register the TL yield in the $2.4 \mathrm{eV}$ band under study, a YGG12 optical filter (Crystaltechno Ltd.) was used with 8\% transmission near $2.32 \mathrm{eV}$ and $\mathrm{FWHM}=0.25 \mathrm{eV}$. In other respects, the measuring technique used for the TL curves was similar to that described above.

\section{Results and discussion}

\subsection{Temperature dependence of the emission spectra in $\alpha-\mathrm{Al}_{2} \mathrm{O}_{3}$}

Fig. 1 shows the temperature dependences of the spectra for luminescence in the triple coordinates "temperature-wavelengthTL intensity" for the untreated and UV-treated sample 1 . The TL signal for sample 1 in the initial state (see Fig. 1a) is described by the known $415 \mathrm{~nm}$ luminescent band $(3.0 \mathrm{eV})$ at $T_{\max }=456 \pm 3 \mathrm{~K}$, which is caused by the F-centers (Evans et al., 1994). However, after the UV treatment of the sample (see Fig. 1b), a contribution of the $335 \mathrm{~nm}$ emission band $(3.7 \mathrm{eV})$ at $T_{\max }=470 \pm 3 \mathrm{~K}$, caused by the $\mathrm{F}^{+}$-centers, is added to the TL signal (McKeever et al., 1999; Weinstein et al., 2002). At the same time, in a green spectral region, the $515 \mathrm{~nm}\left(E_{\max }=2.4 \mathrm{eV}\right)$ luminescence at $T_{\max }=470 \pm 3 \mathrm{~K}$ is observed, with a relatively weak intensity that is thought to be related to the $\mathrm{F}_{2}$ - or $\mathrm{Al}_{i}^{+}$-centers, as specified above in the Introduction.
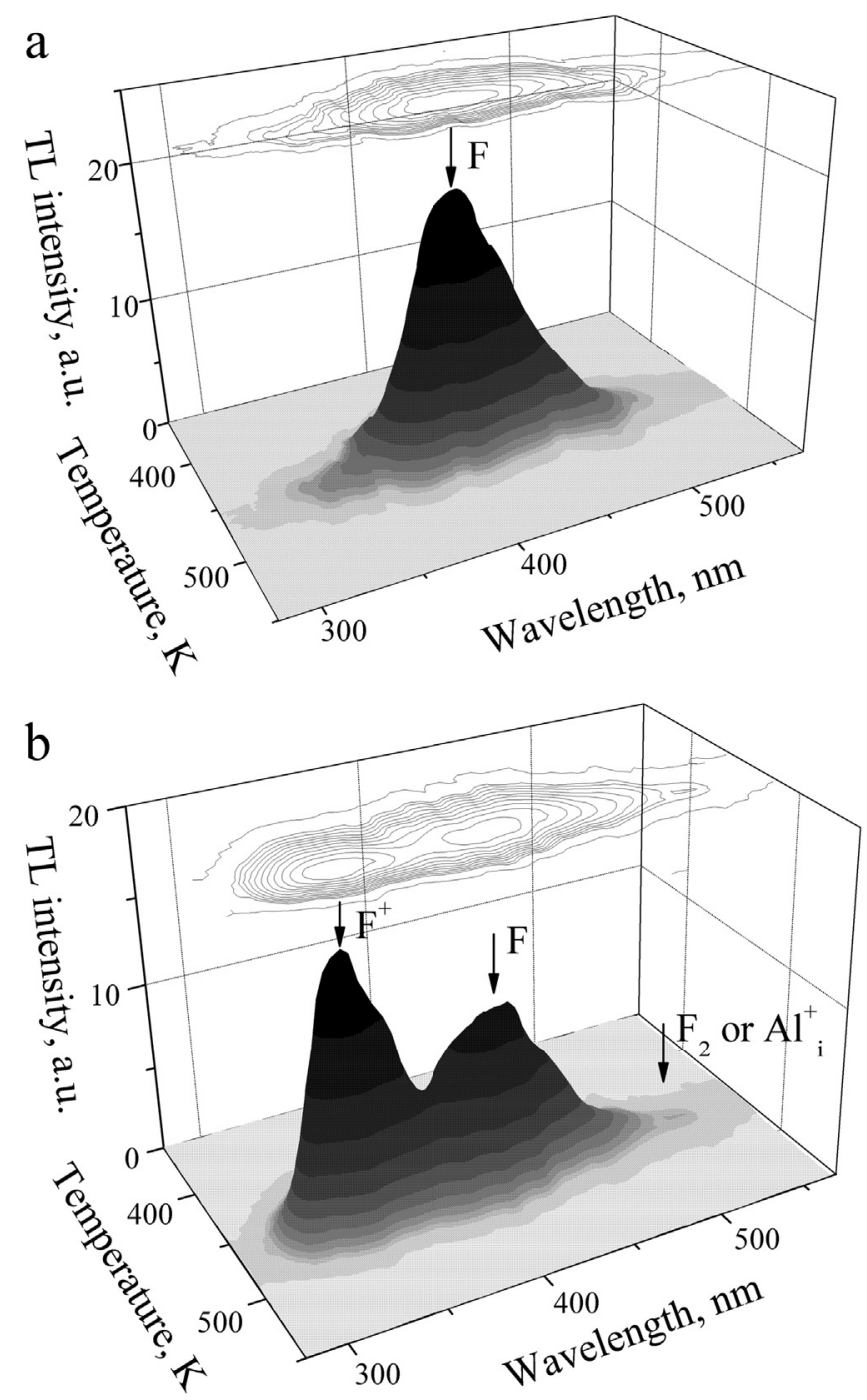

Fig. 1. The spectral dependences of the TL intensity in $\alpha-\mathrm{Al}_{2} \mathrm{O}_{3}$ single crystals (sample 1) before (a) and after (b) UV irradiation at $623 \mathrm{~K}$

For the quantitative analysis of the emission spectral composition, the isothermal sections in the temperature range $470-480 \mathrm{~K}$ were analyzed. In this range, the intensity of F-center luminescence decreases, and the intensity in the $2.4 \mathrm{eV}$ band reaches a maximum. Fig. 2 shows the spectral dependences of the TL intensity for sample 1 at different temperatures. The experimental data are seen to be satisfactorily described by the superposition of independent Gaussians. The decomposition parameters (the maximum energy $E_{\max }$ and the spectral halfwidth $\omega_{\mathrm{E}}$ ) for sample 1 before and after the UV treatment are given in Table 1 .

Note that after the photothermal treatment, the intensity of the $3.7 \mathrm{eV}$ band increases by a factor of 13 and becomes dominant, as observed earlier (McKeever et al., 1999; Weinstein et al., 2002). This effect arises due to the growing concentration of the $\mathrm{F}^{+}$-centers resulting from the UV-induced $\mathrm{F} \rightarrow \mathrm{F}^{+}$-conversion. Simultaneously, in the green spectral region, a band with $E_{\max }=2.38 \mathrm{eV}$ and $\omega_{\mathrm{E}}=0.24 \mathrm{eV}$ is observed. Note that for the initial state of sample 1 , it is impossible to distinguish the $2.4 \mathrm{eV}$ luminescence as a separate component because of the weak intensity and sensitivity of the measuring channel (see Fig. 2a). After the UV irradiation, the TL luminescence of sample 1 in the $2.4 \mathrm{eV}$ band only increases by a factor of 1.5 compared to a sharp jump in the $3.7 \mathrm{eV}$ luminescence. 


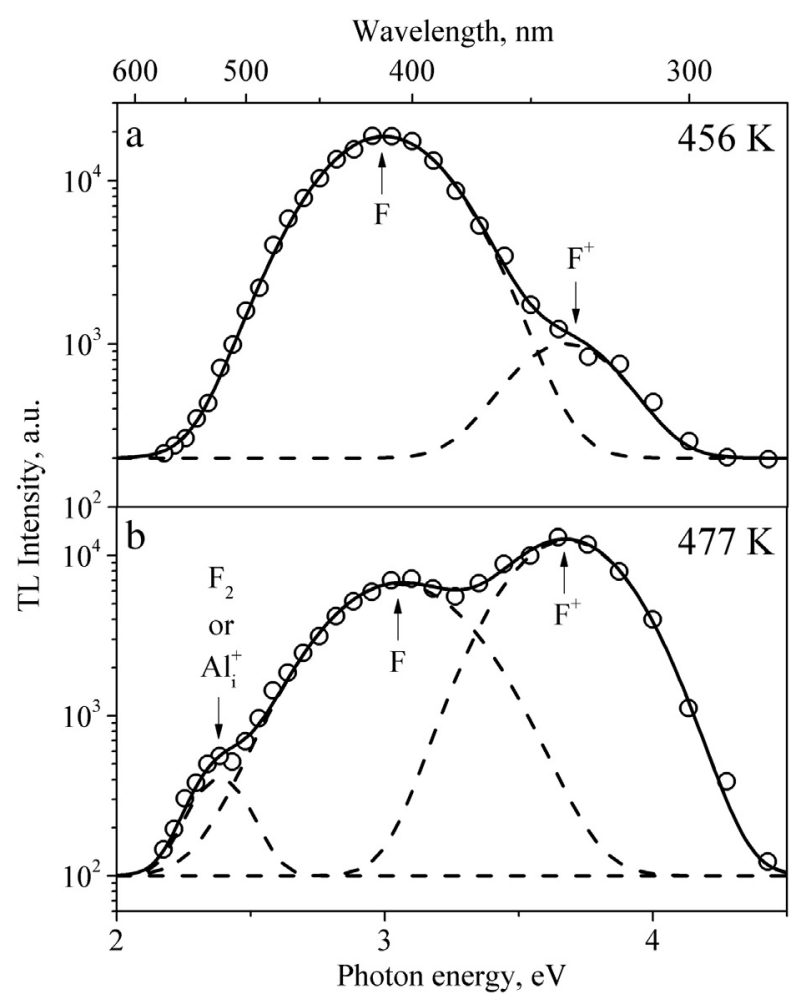

Fig. 2. Isothermal sections of the spectral dependences of the TL intensity before (a) and after (b) the UV treatment of sample 1. Symbols - the experimental values for the maximum intensity of the TL curves. Solid lines - the resulting approximations. Dashed lines - the Gaussian components.

We may therefore conclude that the mechanism of the TL glow in the $2.4 \mathrm{eV}$ band cannot be explained only by a radiative/radiationless transfer of the excitation from the $\mathrm{F}^{+}$-centers. Hence, the identification of this mechanism remains open.

\subsection{Dose dependence in the $2.4 \mathrm{eV}$ band of $\alpha-\mathrm{Al}_{2} \mathrm{O}_{3}$}

As mentioned above, samples 2, 3, and 4 have similar sensitivities in the $3.0 \mathrm{eV}$ band. At the same time, their sensitivities in the $2.4 \mathrm{eV}$ band under study are noticeably different. For example, the sensitivity of sample 2 is more than twofold higher than that of samples 3 and 4. Simultaneously, the maxima of the TL peaks for $D \leq 1 \mathrm{~Gy}$ are within the $470-500 \mathrm{~K}$ range, i.e., the maxima are shifted toward the high-temperature region compared to the $\mathrm{TL}$ glow at $3.0 \mathrm{eV}$, which is conventionally used in dosimetry.

To measure the TL signal, depending on dose in the band under study, we purposefully selected an optical filter (YGG12, Crystaltechno Ltd.) with a transmission of $2.3 \mathrm{eV}$ to eliminate the effect of the $3.0 \mathrm{eV}$ emission. Fig. 3 demonstrates the TL curves in the $2.4 \mathrm{eV}$ band for a given irradiation dose for sample 2. With increasing $D$ within the range under study, the intensity increases to a maximum at $D=3.84 \mathrm{~Gy}$. A further increase in $D$ results in a

Table 1

Values of the TL spectral band for $\alpha-\mathrm{Al}_{2} \mathrm{O}_{3}$.

\begin{tabular}{llll}
\hline Sample state & $E_{\max }, \pm 0.05 \mathrm{eV}$ & $\omega_{\mathrm{E}}, \pm 0.05 \mathrm{eV}$ & Center type $^{\mathrm{a}}$ \\
\hline Untreated & 3.67 & 0.43 & $\mathrm{~F}^{+}$ \\
& 3.05 & 0.53 & $\mathrm{~F}$ \\
UV treated & 3.68 & 0.49 & $\mathrm{~F}^{+}$ \\
& 3.05 & 0.57 & $\mathrm{~F}$ \\
& 2.38 & 0.24 & $\mathrm{~F}_{2}$ or $\mathrm{Al}_{\mathrm{i}}^{+}$ \\
\hline
\end{tabular}

${ }^{a}$ Refs. about defects identification are given in the Introduction.

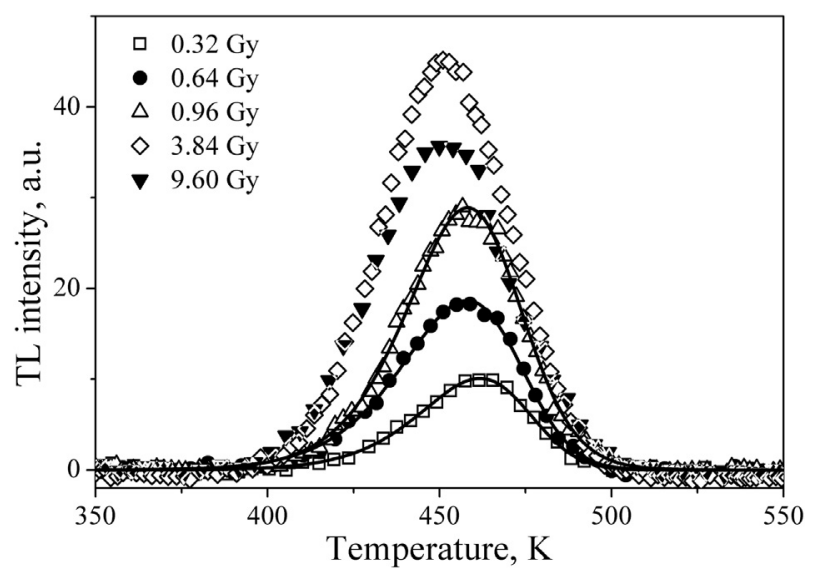

Fig. 3. The TL glow curves in the $2.4 \mathrm{eV}$ band for the variation of the $\beta$-radiation dose. Symbols - the experimental data. Lines - the approximation by the equation of general order kinetics. The doses are shown.

decrease in the luminescence intensity caused by saturation mechanisms.

The TL curve parameters were evaluated for all of the samples under study while varying the irradiation dose. As an example, Fig. 4 presents the dose dependences of the position of the maximum $\left(T_{\max }\right)$, temperature halfwidth $\left(\omega_{\mathrm{T}}\right)$, and form factor $\left(\mu_{\mathrm{g}}\right)$ of the TL peak in the $2.4 \mathrm{eV}$ band for sample 2 . Note that at $D \leq 1 \mathrm{~Gy}$, the values of the parameters remain practically constant and change only within reasonable limits: $T_{\max }=493 \pm 3 \mathrm{~K}$, and $\omega_{\mathrm{T}}=51 \pm 4 \mathrm{~K}$. With a dose increase up to $D=40 \mathrm{~Gy}, T_{\max }$ shifts to a low-temperature region by $40 \mathrm{~K}$, and the TL peak widens by $15 \mathrm{~K}$. This shift and widening of the TL peak with increasing $D$ is a regular process because the dosimetric traps are not monoenergetic and have a depth distribution.

The form factor has similar dependence; $\mu_{\mathrm{g}}=0.43 \pm 0.01$ for $D \leq 1 \mathrm{~Gy}$. This value of $\mu_{\mathrm{g}}$ corresponds to processes with first-order kinetics (Chen and McKeever, 1997). Upon a further dose increase ( $D>1 \mathrm{~Gy}), \mu_{\mathrm{g}}$ increases to 0.5 , and hence, the kinetics order of the processes under study also increases. This fact supports the analysis results of the TL curves (see Fig. 3) in terms of the general-order formal kinetics (Weinstein et al., 2008; Vokhmintsev, 2009). The growth of the kinetics order from 1.0 to 1.5-1.7 upon an increase in the irradiation dose beyond the limits $(D>1 \mathrm{~Gy})$ is explained by the saturation of the dosimetric traps and the growing contribution of competing capture processes in the thermoluminescence mechanism. The dose dependences of the kinetic parameters (the

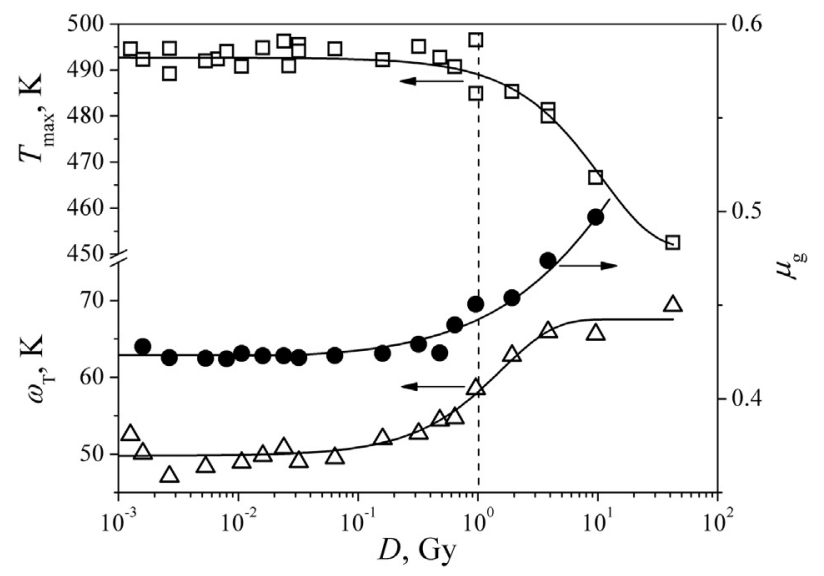

Fig. 4. The TL peak parameters in the $2.4 \mathrm{eV}$ band as a functions of the $\beta$-radiation dose. 


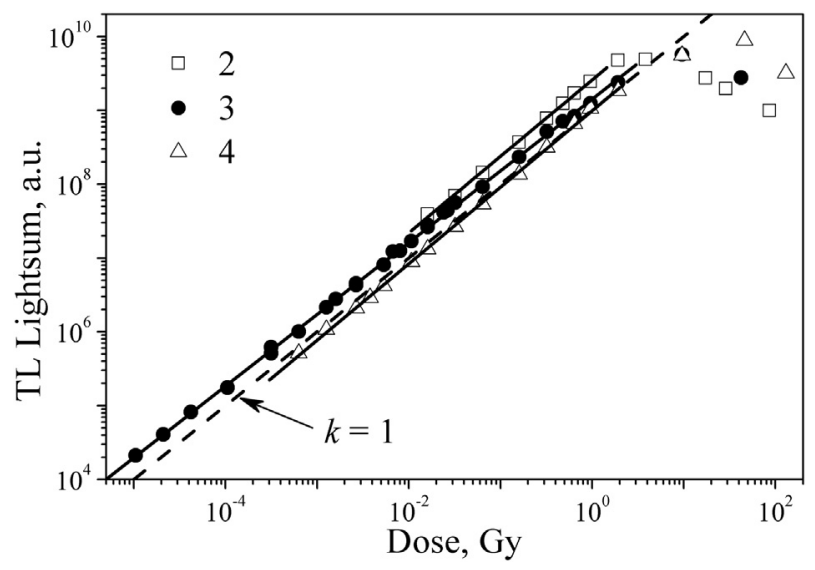

Fig. 5. The dose dependences of the light sum in the $2.4 \mathrm{eV}$ band. Symbols - the values of the light sum obtained from the experimental TL curves. Dashed line - the ideal dose dependence. Solid lines - the line approximations. The sample numbers are shown.

activation energy and the effective frequency factor) in the $2.4 \mathrm{eV}$ band compared to the 3.0 and $3.8 \mathrm{eV}$ band were studied earlier (Weinstein et al., 2008).

The stability of the TL curve parameters $\left(T_{\max }, \omega_{\mathrm{T}}\right.$, and $\left.\mu_{\mathrm{g}}\right)$ observed in the $2.4 \mathrm{eV}$ band for $D \leq 1 \mathrm{~Gy}$ is a very important factor for the evaluation of the absorbed radiation dose. Fig. 5 shows the dose dependences of the TL light sum in the green spectral region for all of the samples under study.

Within the $D \leq 1 \mathrm{~Gy}$ range, the dose characteristics in double logarithmic coordinates are linear with slope coefficients of $k=1.00 \pm 0.04$. For $D>1 \mathrm{~Gy}$, the TL integral response deviates from the ideal dose dependence $(k=1)$. Such a behavior is likely to be related to the saturation of the dosimetric traps at the dose limit. The maximum values of the superlinearity $g(D)=1.2$ and $f(D)=1.3$ have been estimated (Chen and McKeever, 1997). The parameters values close to unity agree with the observed absence of superlinearity on the dose dependences for the band under study (Fig. 5). The absence of superlinearity is a significant practical advantage of the TL luminescence at $2.4 \mathrm{eV}$ to be used in TLD-500 detectors as a stable dosimetric signal to evaluate the absorbed dose (Vokhmintsev et al., 2010a; Vokhmintsev et al., 2010b).

\section{Conclusions}

The effects of photothermal treatment on the spectral and temperature dependences of the luminescence in TLD-500 dosimetric crystals were studied within the $2-4.5 \mathrm{eV}$ range at $300-$ $600 \mathrm{~K}$. It was shown that after an irradiation of the sample with an unfiltered mercury lamp at $623 \mathrm{~K}$ for $30 \mathrm{~min}$, the $\mathrm{F}^{+}$-centers' emission $(3.7 \mathrm{eV})$ dominated in the spectrum of the main dosimetric peak (450-500 K), the intensity of which increased 13 -fold. The observed effect is caused by the thermally assisted $\mathrm{F} \rightarrow \mathrm{F}^{+}$ photoconversion and the intense growth of the single-electron centers' concentration, which is in good agreement with independent data from the literature. It was found that after the abovementioned photothermal treatment, the intensity of the $2.4 \mathrm{eV}$ TL emission in the $\alpha-\mathrm{Al}_{2} \mathrm{O}_{3}$ single crystals also increased 1.5fold. These facts indicate that the TL mechanism in the $2.4 \mathrm{eV}$ band does not solely involve excitation energy transfer from the $\mathrm{F}^{+}$centers.

The kinetic and dosimetric parameters of the TL processes in the $2.4 \mathrm{eV}$ band were analyzed for the single crystals under study depending on the $\beta$-radiation dose within the $D=10^{-5}-10^{2} \mathrm{~Gy}$ range. It was established that the parameters $\left(T_{\max }, \omega_{\mathrm{T}}\right.$, and $\left.\mu_{\mathrm{g}}\right)$ of the experimental TL curves remained practically unchanged for $D \leq 1 \mathrm{~Gy}$. From the above parameters, it was concluded that firstorder kinetic processes prevailed in the thermally stimulated luminescence in the band under study. Upon further growth of the radiation dose to $D>1 \mathrm{~Gy}$, the TL peak shifted toward the lowtemperature region and broadened, and the form factor increased. This result means that the contribution of the competing processes increases significantly.

It is shown that the dose dependences of the TL response in the $2.4 \mathrm{eV}$ band are linear for $D \leq 1 \mathrm{~Gy}$. In this case, the superlinearity region is practically absent as distinct from the parameters measured in the 3.0 and $3.7 \mathrm{eV}$ bands. The possibility of using the $2.4 \mathrm{eV}$ TL emission for the dosimetry of $\beta$-radiation was demonstrated. A slightly marked superlinearity of the dose dependences is an advantage in evaluating the absorbed dose using green thermoluminescence in TLD-500 detectors. This green TL should be investigated in more detail for its other crucial parameters, such as sensitivity, fading, and energy response, to find a specific dosimetric application of this luminescence.

\section{Acknowledgments}

This work was performed in fulfillment of the terms of a State contract under the Federal Program "Scientific and ScientificPedagogical Staff of Innovational Russia 2009-2013". A.S. Vokhmintsev thanks the UrFU Development Program "Provedenie nauchnyh issledovanii molodymi uchyonymi, kandidatami nauk" for their financial support.

\section{References}

Akselrod, M.S., Kortov, V.S., Kravetsky, D.J., Gotlib, V.I., 1990. High sensitive thermoluminescent anion-defective $\mathrm{Al}_{2} \mathrm{O}_{3}: \mathrm{C}$ single crystal detectors. Radiat. Prot. Dosimetry. 32, 15-20.

Arutyunyan, V.V., Babayan, A.K., Belskii, A.N., Gevorkyan, V.A., Makhov, V.N., Martirosyan, U.M., 1995. Luminescence of color centers in $\alpha-\mathrm{Al}_{2} \mathrm{O}_{3}$ single crystals. J. Appl. Spectrosc. 62, 585-588.

Chen, R., McKeever, S.W.S., 1997. Theory of Thermoluminescence and Related Phenomena, Chapter 7. Applications of Thermoluminescence. World Scientific, Singapore.

Evans, B.D., Stapelbroek, M., 1980. Optical vibronic absorption spectra in $14.8 \mathrm{MeV}$ neutron damaged sapphire. Solid State Commun. 33, 765-770.

Evans, B.D., Pogatshnik, G.J., Chen, Y., 1994. Optical properties of lattice defects in $\alpha$ $\mathrm{Al}_{2} \mathrm{O}_{3}$. Nucl. Instrum. Meth. Phys. Res. B 91, 258-262.

Kotomin, E.A., Popov, A.I., 1998. Radiation-induced point defects in simple oxides. Nucl. Instrum. Meth. Phys. Res. B 141, 1-15.

McKeever, S.W.S., Akselrod, M.S., Colyott, L.E., Agersnap Larsen, N., Polf, J.C., Whitley, V., 1999. Characterisation of $\mathrm{Al}_{2} \mathrm{O}_{3}$ for use in thermally and optically stimulated luminescence dosimetry. Radiat. Prot. Dosimetry. 84, 163-168.

Pelenyov, V.E., Kortov, V.S., Milman, I.I., 2001. The interaction of deep traps in aniondefective $\alpha-\mathrm{Al}_{2} \mathrm{O}_{3}$. Radiat. Meas. 33, 629-631.

Springis, M.J., Valbis, J.A., 1984. Visible luminescence of color centres in sapphire. Phys. Status Solid B 123, 335-343.

Tale, I., Piters, T.M., Barboza-Flores, M., Perez-Salas, R., Aceves, R., Springis, M. 1996. Optical properties of complex anion vacancy centers and photo-excited electronic processes in anion defective $\alpha-\mathrm{Al}_{2} \mathrm{O}_{3}$. Radiat. Prot. Dosimetry. 65, 235-238.

Vokhmintsev, A.S., 2009. Thermoluminescence in the $2.4 \mathrm{eV}$ band irradiated aniono-defective aluminum oxide single crystals, $\mathrm{PhD}$ thesis. Ekaterinburg (in Russian).

Vokhmintsev, A.S., Weinstein, IA., Kortov, V.S, 2010a. A method for evaluation of the absorbed radiation dose in thermoluminescent detector based on aniondefective single crystal of aluminum oxide. RF Patent for Invention No. 2378665.

Vokhmintsev, A.S., Weinstein, I.A., Kortov, V.S., 2010b. A device for evaluation of the absorbed radiation dose in thermoluminescent detector based on aniondefective single crystal of aluminum oxide. RF Patent for Invention No. 2378666.

Weinstein, I.A., Pelenyov, V.E., Kortov, V.S., 2002. The effect of thermally stimulated photoconversion of oxygen centers on the sensitivity of TLD-500 dosimetric crystals. Radiat. Prot. Dosimetry. 100, 159-162.

Weinstein, I.A., Vokhmintsev, A.S., Kortov, V.S., 2008. Compensation effect in thermoluminescence of TLD-500. Radiat. Meas. 43, 259-262. 